plant proteins. If such is the case, this effect would be of great interest in animal and human nutrition, especially since deficiencies in trace elements are widespread ${ }^{3}$, as is infant protein malnutrition (kwashiorkor), which appears to be primarily the result of amino-acid deficiency ${ }^{4}$.

In a pilot study, beans (variety, Victory Dwarf Bush) were grown on Robbins's nutrient solution ${ }^{5}$, and on this solution lacking in boron, copper, manganese and zinc respectively. They were harvested when the first fruits appeared, and the proteins were extracted according to the method of Lugg $^{6}$. The proteins were hydrolysed for $12 \mathrm{hr}$. in $6 \mathrm{~N}$ hydrochloric acid and the amino-acid content of the hydrolysate was estimated by a semi-quantitative chromatographic method devised by one of us (H. E. S.). The results are recorded in Fig. 1.

There are indications in this preliminary investigation suggesting that beans grown in a copperdeficient medium have a higher concentration of threonine and perhaps a lower concentration of valine in their protein than normal, whereas beans grown in a zinc-deficient solution have proteins with a very low level of glycine and perhaps isoleucine. Confirmatory experiments are in progress on these and other plants.

We acknowledge the technical assistance of Misses H. Lenz and N. Posthumus.

Department of Botany,

K. H. SCHÜTTE

Department of Medicine,

University of Cape Town.

${ }^{1}$ Mulder, E. G., and Bakema, K., Plant and Soil, 7, 135 (1956).

${ }^{2}$ Sheldon, V. L., Blue, W. G., and Albrecht, W. A., Plant and Soil, 3, 33 (1951); Chem. Eng. News, 28, 4077 (1950). Mulder, E. G., Atti del Congresso Internazionale di Microbiologia, Rome, 6, Sect. 18, 293 (1953)

${ }^{3}$ Schütte, K. H., Sols africains, 3, 2 (1955).

4 Schütte, K. H., S.A. Med. J., 29, 595 (1955). Brock, J. F., Hansen J. D. L., Howe, E. E., Davel, J. G. A., Pretorius, P. J., and Hendrickse, R. G., Lancet, ii, 355 (1955).

${ }^{5}$ Robbins, W. R., Soil Sci., 62, 3 (1946).

${ }^{6}$ Lugg, J. W. H., Biochem. J., 33, 110 (1939).

\section{Retention of Food Residues in the Midgut by Nymphs of the Milkweed Bug, Oncopeltus fasciatus Dall.}

DURING experiments on the nutrition of Oncopeltus fasciatus, in the course of which both nymphs and adults ingested solutions containing a fine suspension of Chinese black, it was noticed that only the adults voided black fæces, and that newly moulted adults voided a particularly thick black mass within two days of ecdysis. In a confirmatory experiment, the insects were reared from the egg on milkweed seed and a water-suspension of Chinese black, and their excreta were collected on the filter paper shown in

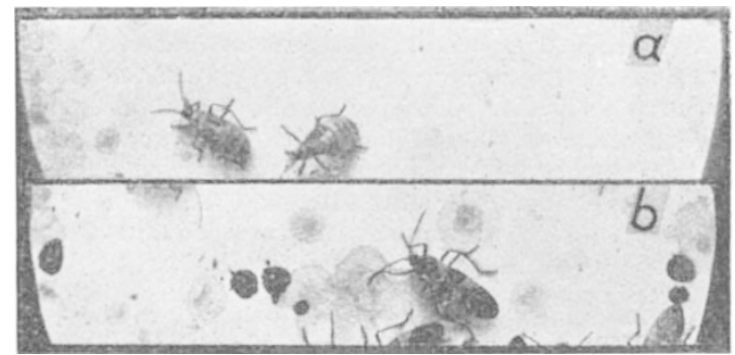

Fig. 1. The accumulated excreta of Oncopeltus reared on milkweed reed and a water-ginspension of Chinese black: $(a)$ just before and $(b)$ after the majority had become adult
Fig. 1. By the time the first adults had appeared, only watery material had been excreted, whereas three days later, when nearly all had moulted, black fæcal masses were evident.

Examination of the nymphs showed that particles of Chinese black became concentrated in the third region of the midgut. It was also found that in mature nymphs which had fed on an abundance of milkweed seed, whether or not they had ingested Chinese black, this region was distended, had a flourishing bacterial flora, and contained a large droplet of oil. The short, narrow region (which has been called a 'fourth stomach'1) connecting the third region of the midgut to the 'pylorus' appeared, at this stage, to be histologically fully formed, but closed, although traces of a lumen could be made out along most of its length. In adults, the third region of the midgut did not reach the dimensions of that in the mature nymph, its bacterial flora was greatly depleted, and it was never found to contain a droplet of oil.

It appears, therefore, that in Oncopeltus the residues of nymphal meals accumulate in the third region of the midgut, to be voided soon after the final ecdysis. This does not seem to have been recognized previously, possibly because the nymphs excrete drops which contain reddish-brown solid matter, and these can be mistaken for true fæces, although they lack the thicker consistency of the latter and almost certainly originate entirely in the Malpighian tubes.

Many phytophagous Heteroptera possess special features associated with the last region of the midgut, such as cæca or inwardly directed filaments ${ }^{2}$, which are lacking in Oncopeltus. It would be interesting to know, therefore, whether, in these cases, food residues are also retained in the nymphal midgut, since it is possible that the retention in Oncopeltus is concerned with ensuring the efficient extraction of nutrients from a simpler form of gut.

\section{Zoological Laboratory,}

Cambridge. Aug. 5 .

* Present address: Waite Agricultural Research Institute, University of Adelaide.

${ }^{1}$ Hood, C. W., Ohio J. Sci., 37, 151 (1937).

2 Goodchild, A. J. P., Proc. Zool. Soc. Lond., 122, 543 (1952).

\section{Composition of the Cell Wall of Staphylococcus aureus 209P}

RECENTLY, Park and Strominger ${ }^{1}$ assumed that uridine-diphosphate compounds extracted from cells of Staphylococcus aureus $H$ treated with penicillin are the precursors of the cell wall, because the cell wall and one of their compounds contained muramic acid, alanine, glutamic acid and lysine in the ratio of $1: 3: 1: 1$. But the cell wall also contained glycine (ratio $3: 8$ ).

We found ${ }^{2}$ that similar uridine-diphosphate compounds were accumulated in another strain of $S$. aureus treated with penicillin, but these compounds contained five amino-acids : alanine, glycine, lysine, aspartic and glutamic acid in various combinations. As it seems probable that there is a certain variation in the amino-acid composition of cell walls among different strains of a single bacterial species ${ }^{3}$, a study was made of the amino-acid composition of the cell wall of the present strain to confirm the assumed correlation between the accumulated compounds and cell walls. 